Глава 7. Защита растений

УДК 632.792(1-924.71)

doi: 10.31360/2225-3068-2018-67-217-226

OPHELIMUS MASKELLI (ASHMEAD, 1900)

(HYMENOPTERA: EULOPHIDAE) - НОВЫЙ ИНВАЗИВНЫЙ ВРЕДИТЕЛЬ ЭВКАЛИПТА

В КРЫМУ

\author{
Никулина Т. В., Мартынов В. В. \\ Государственное учреждение "Донеиякий ботанический сад» \\ г. Донеик, Донеикая Народная Республика, e-mail: nikulinatanya@mail.ru
}

В работе приведены данные о первой находке инвазивного вида Ophelimus maskelli (Ashmead, 1900) в Крыму, проанализирована история его экспансии за пределы первичного ареала, особенности биологии и хозяйственное значение. Предположительно, проникновение вида на территорию Крыма является результатом завоза поражённых саженцев E. viminalis Labill. в Никитский ботанический сад из Италии в 2012 г. Поражённость листьев колебалась от 20 до 300 галлов/лист (в среднем 104,3 $\pm 14,1$ ), 97 \% листьев были сильно поражёнными (более 40 галлов/лист).

Ключевые слова: Ophelimus maskelli, Крым, эвкалипт, первая находка, инвазия.

Естественный ареал растений рода Eucalyptus L'Héritier, 1788 ограничен Австралией, Индонезией, Филиппинами и Новой Гвинеей, однако благодаря интродукции они стали одними из наиболее широко распространённых лиственных древесных пород в мире. Эвкалипты культивируют во многих субтропических и тропических странах как быстрорастущую высокопроизводительную породу, дающую ценную древесину, эфирные масла, дубильные вещества и др. За последние 150 лет в Северную Америку (преимущественно в Калифорнию и Флориду) было интродуцировано порядка 90 видов этого рода [19]. На Черноморское побережье Кавказа в течение столетия, начиная с 80-х гг. XIX в., было интродуцировано порядка 150 видов эвкалипта [6], из которых в настоящее время культивируется порядка 90 видов и гибридов $[1,2]$. В СССР наиболее активно работы по интродукции эвкалиптов проводились в 30-40-х гг. XX в. в рамках программы по осушению колхидских болот - очагов малярии. В этот период в Абхазии, Аджарии и западной Грузии было высажено более 10 миллионов эвкалиптов.

В Крым эвкалипты были впервые завезены в 1816 г., но не прижились и лишь весной 1949 г. большое количество семян и саженцев вновь были завезены на полуостров из района г. Сочи [5]. 
Несмотря на широкую интродукцию, эвкалипты длительное время избегали достаточно разнообразного комплекса специализированных фитофагов-вредителей, связанных с ними в пределах естественного ареала. Этому во многом способствовала географической изоляция природных популяций и в не меньшей мере тот факт, что интродукция на начальном этапе проводилась семенами.

Ситуация принципиально изменилась в XX веке, что связано с формированием обширной сети питомников по разведению эвкалиптов во всех тропических и субтропических регионах мира и активным использованием контейнерных культур для транспортировки посадочного материала. Как следствие, в европейско-средиземноморский регион к настоящему времени проникли 6 инвазивных видов насекомых, трофически связанных с эвкалиптами. К наиболее ранним вселенцам относится жук-усач Phoracantha semipunctata (Fabricius, 1775) (Coleoptera: Cerambycidae), проникший в Северную Африку в начале 1940-х гг. В 1960-х гг. в западное Средиземноморье проникла псиллида Ctenarytaina eucalypti (Maskell, 1890) (Hemiptera: Spondyliaspinidae), a в 1975 г. - жук-долгоносик Gonipterus scutellatus (Gyllenhal, 1833) (Coleoptera: Curculionidae). В 1999 г. в Тунисе был обнаружен еще один вид жуков-усачей - Phoracantha recurva Newman, 1840. Последними, на границе XX и XXI вв., в Средиземноморье проникли два вида галлообразующих перепончатокрылых: Leptocybe invasa Fisher \& LaSalle, 2004 и Ophelimus maskelli (Ashmead, 1900) (Hymenoptera: Eulophidae) [33].

В сентябре 2018 г. при обследовании коллекции древесно-кустарниковых растений Никитского ботанического сада (г. Ялта, пгт Никита) был впервые выявлен Ophelimus maskelli (Ashmead, 1900) (Hymenoptera: Eulophidae) - специфический вредитель эвкалипта. По данным сотрудников Никитского ботанического сада, саженцы эвкалипта прутовидного (Eucalyptus viminalis Labill.), на котором был нами обнаружен O. maskelli, были получены в 2012 г. из Италии.

Распространение (рис. 1). Родиной O. maskelli, как и его кормового растения, является Австралия. В Европе этот вид был впервые обнаружен 1999 г. в Италии и ошибочно идентифицирован как O. eucalypti [8; 38], однако по мнению ряда авторов [22], указание неизвестного вида Ophelimus для г. Альбиния (Италия), отловленного в 1998 г. на Eucalyptus camaldulensis [11], следует также относить к O. maskelli. В 2000 г. выявлен на о. Сицилия [12], в 2001 г. - в Испании и на Балеарских о-вах [36], в 2002 г. - в Греции [23], в 2004 г. на о. Корсика [31], в 2005 г. - во Франции [20] и Великобритании [10], в 2006 г. - на о. Мальта [30], о. Сардиния [16] и в Португалии [13], в 2011 г. - в России на Черноморском побережье 
Кавказа [4]. Для Ближнего Востока O. maskelli впервые указан из Израиля в 2003 г. [33], в Турции выявлен в 2006 г. [18], в Иордании - в 2012 г. [21], в Сирии - в 2014 г. [37], в Ираке - в 2016 г. [25]. Для Африканского континента указан из Марокко по находкам, сделанным в 2002 г. [24], в Тунисе известен с 2006 г. [17], в Алжире - с 2008 г. [15], в Эфиопии - с 2017 г. [9]. Завезён в Южную Америку, где выявлен в Чили в 2003 г. и в Аргентине в 2013 г. [7], в 2014 г. был зарегистрирован в Северной Америке на территории США в Калифорнии [14].

Биология. O. maskelli - партеногенетический поливольтинный вид. На Сицилии отмечено развитие двух генераций [28], в Израиле, Иордании и в условиях влажных субтропиков Черноморского побережья России развиваются 3 генерации [4, 21, 33].

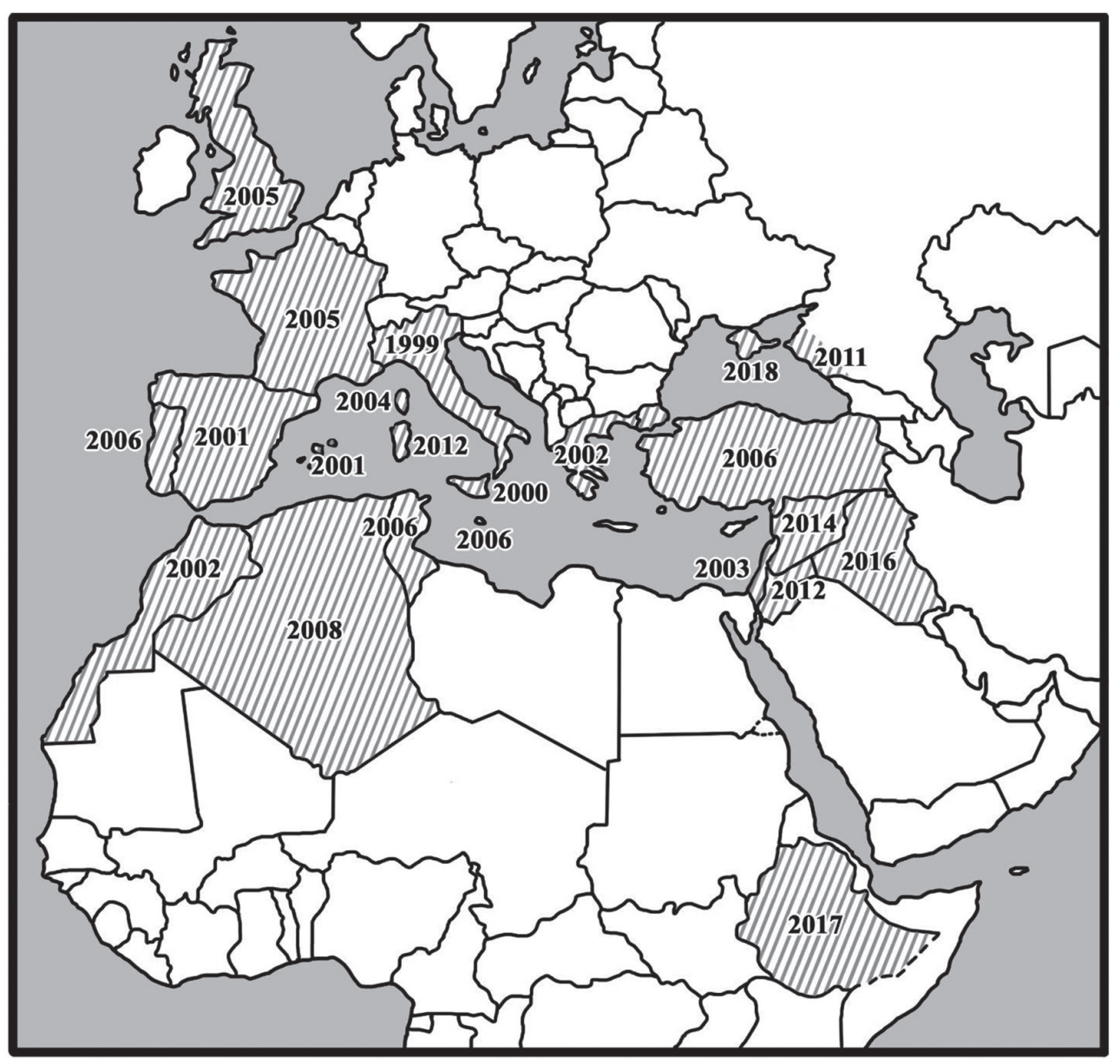

Рис. 1. Вторичный ареал Ophelimus maskelli (Ashmead, 1900) в Восточном полушарии 
Наиболее высокая агрессивность и плодовитость характерна для первой генерации [3]. Откладка яиц происходит, как правило, на верхней стороне листьев в утреннее и дневное время. Плодовитость самок колеблется от 60 до 110 яиц. Предпочтительными для откладки яиц являются листья, достигшие максимального размера и в то же время имеющие типичный для молодых листьев зелёный цвет (от 15 до 70 дней после распускания почек). В каждом галле развивается только одна личинка.

Цикл развития O. maskelli можно условно разделить на 5 основных этапов. Первый этап длится 30-35 дней - с момента откладки яйца до появления первых видимых признаков начала формирования галла. На втором этапе, который продолжается 15-25 дней, на листовой пластике появляется прозрачная область мезофилла, ткань галла начинает слегка выступать над поверхностью листовой пластинки, к концу этапа галлы на хорошо освещённых листьях приобретают характерную яркую окраску. На третьем этапе, продолжающемся 16-27 дней, галл достигает максимальных размеров и проявляется как на верхней, так и на нижней стороне листа. На четвёртом этапе, который длится 20-26 дней, личинка достигает максимальных размеров, занимая большую часть галла, в конце этапа происходит окукливание. Последний (пятый) этап длится 10-16 дней и оканчивается выходом имаго. В целом жизненный цикл O. maskelli завершатся за 100-120 дней [33].

В пределах естественного ареала O. maskelli развивается на эвкалипте камальдульском - Eucalyptus camaldulensis Dehnh., широко распространённом по всей территории Австралии, однако в условиях вторичного ареала он расширил спектр кормовых пород и к настоящему времени зарегистрирован еще на 16 видах эвкалипта (табл. 1). Как видно из таблицы, к наиболее поражаемым породам, помимо E. camaldulensis, относятся E. globulus и E. viminalis, в значительной степени подвержены нападению E. botryoides, E. grandis, E. robusta, E. saligna и E. tereticornis.

При массовом развитии $O$. maskelli степень поражённости растений может достигать нескольких сотен галлов/лист. Например, в Испании степень поражённости E. camaldulensis достигала 647 галлов/лист, составляя в среднем 92,4 $\pm 161,6$ галла/лист [15], на Сицилии для этого же кормового растения было зарегистрировано развитие 158 галлов/лист [28], в Израиле - 133,5 $\pm 98,7$ [33], в Алжире - 6,5 $\pm 7,1$ [15].

Наши исследования показали, что степень поражённости листьев E. viminalis в Никитском ботаническом саду колебалась от 20 до 300 галлов/лист, составив в среднем 104,3 $\pm 14,1$ галла/лист. Непоражёнными были только молодые, недавно раскрывшиеся листья. По принятой в ряде работ шкале оценки плотности поражения [33], 97 \% листьев в изученной выборке относятся к категории сильно поражённых, т. е. имеют более 40 галлов/ лист, и только 3 \% - к слабо поражённым (менее 40 галлов/лист). 


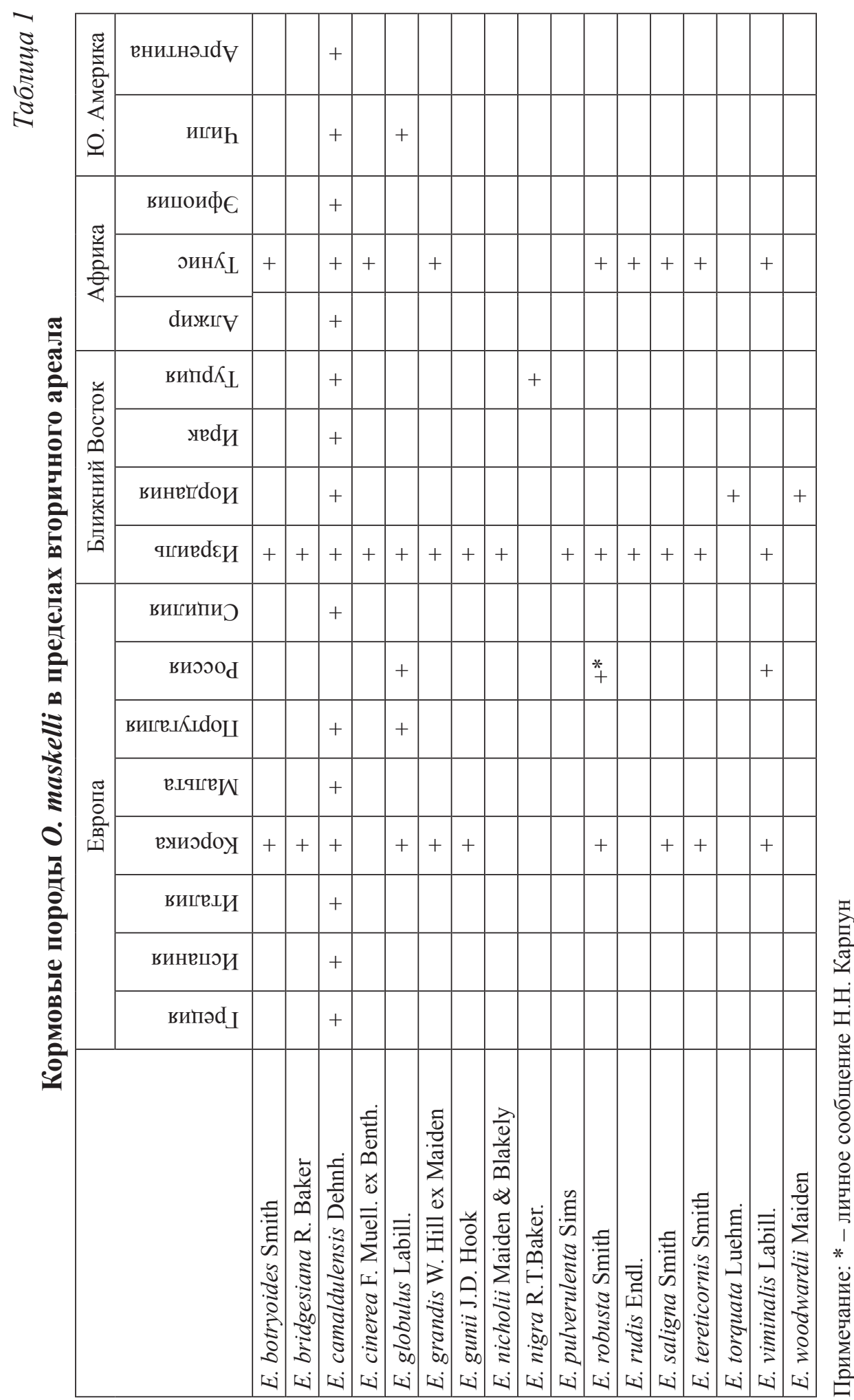


Хозяйственное значение. O. maskelli вначале заселяет нижний ярус кроны, но при нарастании численности атакует всё дерево. К моменту достижения личинкой 3-го возраста галлы на хорошо освещённых листьях приобретают характерный малиновый цвет, придавая поражённым листьям красноватый оттенок. Галлы на теневых листьях остаются зелёными или зеленовато-жёлтыми. Диаметр галла составляет от 0,9 до 1,2 мм. При массовом размножении вся поверхность листа сплошь покрывается галлами $[3,33]$. В наибольшей степени $O$. maskelli вредит молодым растениям в питомниках $[21,28,33]$.

Кроме того, развитие галлов $O$. maskelli сокращает продолжительность жизни листьев эвкалипта более чем в 3 раза: если в норме они функционируют до 9-11 месяцев, то при сильном поражении усыхание и опадение наступает к 4-месячному возрасту. При массовом нападении известны случаи полной дефолиации эвкалиптов в Израиле [33].

По данным, полученным в Израиле [33], взрослые особи при массовом лёте способны провоцировать проблемы со здоровьем у людей вблизи сильно заселённых деревьев. Районы, окруженные декоративными насаждениями эвкалипта, сильно страдают от облаков имаго во время пиков лётной активности. Это явление приобретает такие масштабы, что возникает необходимость отмены занятий в школах. Привлекательность зелёного цвета для имаго, вероятно, является причиной их массового появления на сельскохозяйственных культурах, окружённых насаждениями эвкалиптов. Имаго, привлекаемые зелёным цветом, создают трудности при реализации сельскохозяйственной продукции (салат и др.).

Методы борьбы. К настоящему времени в странах Европы и Средиземноморья разработан целый комплекс защитных мероприятий, направленный на снижение и контроль численности O. maskelli.

В качестве механических методов контроля широко применяют зелёные клеевые ловушки, действие которых основано на привлекательности зелёного цвета для имаго [3; 33]. Некоторые исследователи рекомендуют на молодых растениях, особенно в питомниках, использовать каолиновую пудру [28].

В качестве химических методов контроля для защиты эвкалиптов рекомендуются обработки препаратами на основе имидаклоприда (конфидор экстра, ВДГ (15 г препарата на 10 л воды), командор, ВРК (15 мл препарата на 10 л воды) или хлорпирифоса (дурсбан, КЭ; сайрен, КЭ - 20 мл на 10 л воды) [3].

К настоящему времени наиболее широкие масштабы приобрели методы биологического контроля численности O. maskelli. По 
Глава 7. Защита растений

данным исследователей из Израиля [33], на начальных этапах инвазии $O$. maskelli не имел паразитов (за исключением редких случаев поражения Megastigmus sp.). В 2003 г. в рамках совместного проекта Израиля и Австралии была запущена программа поиска естественных врагов O. maskelli с целью их дальнейшего использования в качестве агентов биологической борьбы в Европе. В 2005 г. на территории Израиля были выпущены два вида паразитоидов: Closterocerus chamaeleon (Girault, 1922) (Hymenoptera: Eulophidae) и Stethynium ophelimi Huber, 2006 (Hymenoptera: Mymaridae) [16, 29, 32]. В 2006 г. C. chamaeleon был выпущен в Италии [26], на Сицилии [34] и Сардинии [16]. За несколько месяцев C. chamaeleon натурализовался во всех местах выпуска и продемонстрировал высокую скорость расселения, проникнув в Турцию, Испанию, Алжир [15], Португалию [13], Тунис [27], Сирию [37]. Это вид присутствует также в Аргентине [7] и Калифорнии [14].

С самого начала эксперимента C. chamaeleon проявил себя как высокоэффективный контролер численности своего хозяина. В Израиле уже через год после его выпуска отмечалось значительное уменьшение количества поражённых листьев на 1 ветвь (73,1 до 38,3 \%). Исследования, проведённые на Сицилии, показали, что в течение двух лет $C$. chamaelon оказался способным снизить численность своего хозяина в 5 раз [35]. В Португалии степень заражённости O. maskelli паразитоидом колебалась от 9,6 до 63,5 \% [13].

В настоящее время для территории России C. chamaelon отмечен не был, однако с учётом высокой скорости саморасселения, в ближайшие годы следует ожидать его появления сначала на Черноморском побережье Кавказа, а затем и в Крыму.

Авторы выражают искреннюю признательность сотрудникам Никитского ботанического сада О. М. Шевчук и В. Н. Герасимчуку за организацию экскурсий и консультативную помощь.

\section{Библиографический список}

1. Айба Л.Я. Губаз Э.Ш. Перспективные субтропические культуры в Абхазии. - Сухум, 2017. $-246 \mathrm{c}$.

2. Карпун Ю.Н. Субтропическая декоративная дендрология: справочник. - СПб.: BBM, 2010. - 580 c. - ISBN: 978-5-9651-0000.

3. Карпун Н.Н., Айба Л.Я., Журавлёва Е.Н., Игнатова Е.А., Шинкуба М.Ш. Руководство по определению новых вредителей декоративных древесных растений на Черноморском побережье Кавказа / под ред. Б.А. Борисова. - Сочи-Сухум, 2015. - 78 с. - ISBN: 978-5-904533-23-6. 
4. Карпун Н.Н., Журавлёва Е.Н., Игнатова Е.А., Тарба Ф.Т. Новые инвайдеры-фитофаги эвкалипта в субтропиках Черноморского побережья России // Труды ботанического института. - Вып. II. - Сухум: РУП «Дом печати», 2014. - С. 97-109.

5. Пилипенко Ф.С. Род 9. Эвкалипт - Eucalyptus L'Héritier // Деревья и кустарники CCCP. Дикорастущие, культивируемые и перспективные для интродукции. T.V. Покрытосеменные. Семейства Миртовые - Маслиновые. - М., Л: Изд-во АН СССР, 1960. - C. 24-132.

6. Шишкин Б.К. Род эвкалипт - Eucalyptus // Флора СССР. Т. XV. - М., Л: Изд-во АН CCCP, 1949. - C. 558-565.

7. Aquino D.A., Hernánde C.M., Cuello E.M., Andorno A.V., Botto E.N. Primera cita de la Argentina de Ophelimus maskelli (Ashmead) (Hymenoptera: Eulophidae) y su parasitoide, Closterocerus chamaeleon (Girault) (Hymenoptera: Eulophidae) // Revista de la Sociedad Entomológica Argentina, 2014. - Vol. 73. - № 3-4. - P. 179-182.

8. Arzone A., Alma A. Eulofíde galligeno dell'Eucalipto in Italia // Informatore Fitopatologico, 2000. - Vol. 50. - № 12. - P. 43-46.

9. Asfaw B.A. First Record of Eucalyptus Gall Wasp (EGW) (Ophelimus maskelli) (Ashmead) on Eucalyptus camaldulensis in Ethiopia // International Journal of Agriculture and Forestry, 2018. - Vol. 8. - № 2. - P. 112-117.

10. Badmin J. Spread of Ophelimus maskelli Ashmead (Hymenoptera: Eulophidae) in south-east England // British Journal of Entomology and Natural History, 2008. - Vol 21. - № 3. - P.147.

11. Bagnoli B., Roversi P.F. Annotazioni morfologiche e biologiche su un Eulofide di recente introduzione in Italia galligeno fogliare su Eucalipto // Atti XIX Congresso nazionale italiano di Entomologia, Catania, 10-15 giugno 2002. - Sondrio: Polaris, 2004. - P. 955-960. 12. Bella S., Lo Verde G. Presenza nell'Italia continentale e in Sicilia di Ophelimus prope eucalypti e Aprostocetus sp., galligeni degli Eucalipti (Hymenoptera: Eulophidae) // Naturalista siciliano, 2002. -Vol. 26. - № 3-4. - P. 191-197.

13. Branco M., Boavida C., Durand N., Franco J.C., Mendel Z. Presence of the Eucalyptus gall wasp Ophelimus maskelli and its parasitoid Closterocerus chamaeleon in Portugal: first record, geographic distribution and host preference // Phytoparasitica, 2009. - Vol. 37. - Issue 1. - P. 51-54.

14. Burks R.A., Mottern J.L., Waterworth R., Paine T.D. First report of the Eucalyptus gall wasp Ophelimus maskelli (Hymenoptera: Eulophidae), an invasive pest on Eucalyptus, from the Western Hemisphere // Zootaxa, 2015. - Vol. 3926. - P. 448-450.

15. Caleca V. First record in Algeria of two eulophid wasps: Closterocerus chamaeleon (Girault) and its host, the eucalyptus gall wasp Ophelimus maskelli (Ashmead) (Hymenoptera: Eulophidae) // Naturalista siciliano, 2010. - Vol. 34. - № 1-2. - P. 201-206.

16. Caleca V., Rizzo M.C., Lo Verde G., Rizzo R., Buccellato V., Luciano P., Cao O., Palmeri V., Grande S.B., Campolo. O. Diffusione di Closterocerus chamaeleon (Girault) introdotto in Sicilia, Sardegna e Calabria per il controllo biologico di Ophelimus maskelli (Ashmead) (Hymenoptera: Eulophidae), galligeno esotico sugli eucalipti // Atti del Terzo Congresso Nazionale di Selvicoltura per il miglioramento e la conservazione dei boschi italiani, Taormina, 16-19 ottobre 2008. - Vol. 3. - Firenze, 2009. - P. 638-642.

17. Dhahri S., Ben Jamaa M.L., Lo Verde G. First record of Leptocybe invasa and Ophelimus maskelli eucalyptus gall wasps in Tunisia // Tunisian Journal of Plant Protection, 2010. - Vol. 5. - P. 229-234.

18. Doğanlar O., Mendel Z. First record of the Eucalyptus gall wasp Ophelimus maskelli and its parasitoid, Chosterocerus chamaeleon in Turkey // Phytoparasitica, 2007. - Vol. 35. - Issue 4. - P. 333-335. 
19. Doughty R.W. The eucalyptus: a natural and commercial history of the gum tree. - Baltimore: The Johns Hopkins Univ. Press, 2000. - 237 p.

20. First report of two new eucalyptus pests in the south of France: Ophelimus maskelli and Leptocybe invasa. - EPPO Reporting Service, 2006. - № 9. - Access mode: https://gd.eppo. int/reporting/article-1236

21. Husni G.I., Araj A.S.-E. Population trend, host susceptibility and damage study on the eucalyptus gall wasp Ophelimus maskelli (Ashmead) (Hym., Eulophidae) in Jordan // Jordan Journal of Agricultural Sciences, 2016. - Vol. 12. - № 1. - P. 239-248.

22. Inghilesi A.F., Cervo R., Pennacchio F., Roversi P.F., Tricarico E., Mazza G. Alien insects on Eucalytpus spp.: an australian biocenosis in Tuscany // Redia, 2013. - Vol. XCVI. - P. 21-26. 23. Kavallieratos N.G., Kontodimas D.C., Anagnou-Veroniki M., Emmanouel N.G. First record of the gall inducing insect Ophelimus eucalypti (Gahan) (Hymenoptera: Chalcidoidea: Eulophidae) in Greece // Annals of the Benaki Phytopathological Institute (N.S.). 2006. - Vol. 20. - P. 125-128.

24. Kissayi K., Benhalima S. Ophelimus maskelli (Ashmead) et son parasitoïde Closterocerus chamaeleon (Girault) (Hymenoptera: Eulophidae) au Maroc // Bulletin OEPP/EPPO Bulletin, 2018. - Vol. 48. - № 2. - P. 293-299.

25. Lahouf A.A., El-Seweydi T.M.M., El-Jboory I.J. First record of the Eucalyptus gall wasp Ophelimus maskelli (Ashmead) in Kerbala province, Iraq // Arab Journal of Plant Protection, 2018. - Vol. 36. - № 2. - P. 123-125.

26. Laudonia S., Viggiani G., Sasso R. Parassitoide esotico in aiuto degli eucalypti // Informatore Agrario, 2006. - № 61(40). - P. 74.

27. Lo Verde G., Dhahri S. Ben Jamaa M.L. First record in Tunisia of Closterocerus chamaeleon (Girault) parasitoid of the eucalyptus gall wasp Ophelimus maskelli (Ashmead) (Hymenoptera: Eulophidae) // Naturalista siciliano. - 2010. -Vol. 34. - № 1-2. - P. 207-210. 28. Lo Verde G., Rizzo R., Barraco G. Dannosità e controllo di Ophelimus maskelli (Ashmead) su Eucalyptus camaldulensis in vivaio // Atti del Terzo Congresso Nazionale di Selvicoltura per il miglioramento e la conservazione dei boschi italiani, Taormina, 16-19 ottobre 2008. - Vol. 3. - Firenze, 2009. - P. 1409-1412.

29. Mendel Z., Protasov A., Blumberg D., Brand D., Saphir N., Madar Z., La Salle J. Release and recovery of parasitoids of the eucalyptus gall wasp Ophelimus maskelli in Israel. Phytoparasitica. - 2007. - Vol. 35. - Issue 4. - P. 330-332.

30. Mifsud D. Leptocybe invasa Fisher \& La Salle, 2004 and Ophelimus maskelli Haliday, 1844 - two new records of gall forming Eulophidae from Malta (Hymenoptera: Chalcidoidea) // Bulletin of the Entomological Society of Malta, 2012. - Vol. 5. - P. 189-193.

31. Ophelimus maskelli (Ashmead) // La Fredon Corse, 2004. - Access mode: http://www. fredon-corse.com/ravageurs/Ophelimus-maskelli.htm

32. Protasov A., Blumberg D., Brand D., Lasalle J., Mendel Z. Biological control of the eucalyptus gall wasp Ophelimus maskelli Ashmead: Taxonomy and biology of the parasitoid species Closterocerus chamaeleon (Girault), with information on its establishment in Israel // Biological Control, 2007. - Vol. 42. - P. 196-206.

33. Protasov A., La Salle J., Blumberg D., Brand D., Saphir N., Assael F., Fisher N., Mendel Z. Biology, revised taxonomy and impact on host plants of Ophelimus maskelli, an invasive gall inducer on Eucalyptus spp. in the Mediterranean area // Phytoparasitica, 2007. Vol. 35. - Issue 1. - P. 50-76.

34. Rizzo M.C., Lo Verde G., Rizzo R., Buccellato V., Caleca V. Introduzione di Closterocerus sp. in Sicilia per il controllo biologico di Ophelimus maskelli Ashmead (Hymenoptera: Eulophidae) galligeno esotico sugli eucalipti // Bollettino di zoologia agrarian e di bachicoltura. - 2006. - Ser. II. - Vol. 38(3). - P. 237-248. 
35. Sasso R., Laudonia S., Viggiani G. Dati preliminari sul controllo biologico di Ophelimus maskelli (Ashmead) (Hymenoptera: Eulophidae) in Campania a seguito dell'introduzione del suo antagonista Closterocerus chamaeleon (Girault) (Hymenoptera: Eulophidae) // Bollettino del laboratorio di entomologia agraria Filippo Silvestri. - 2006. - Vol. 62. - P. 51-55.

36. Situation of recently introduced pests in Spain. EPPO Reporting Service, 2010. - № 3. - Access mode: https://gd.eppo.int/reporting/article-429

37. Trissi A.N., Shehadi F. First record of two gall-inducing wasps on Eucalyptus (Eucalyptus sp.) in Syria // Arab Journal of Plant Protection, 2014. - Vol. 32. - № 1. - P. 92-95. 38. Viggiani G., Nicotina M. The eulophid leaf gallmaking of eucalyptus Ophelimus eucalypti (Gahan) (Hymenoptera: Eulophidae) in Campania // Bollettino di Zoologia Agraria e di Bachicoltura, 2001. - Vol. 33. - P. 79-82.

\title{
OPHELIMUS MASKELLI (ASHMEAD, 1900) (HYMENOPTERA: EULOPHIDAE) - A NEW INVASIVE PEST OF EUCALYPTUS IN CRIMEA
}

\author{
Nikulina T. V., Martynov V. V. \\ State institution "Donetsk Botanical Garden”, \\ c. Donetsk, Donetsk People's Republic, e-mail: nikulinatanya@mail.ru
}

The paper presents some data on the first record of invasive species Ophelimus maskelli (Ashmead, 1900) in Crimea; we analyzed the history of its expansion outside the primary range, its biological features and economic importance. Probably, the penetration of the species into the territory of Crimea was the result of the importation of the infested E. viminalis Labill. seedlings into the Nikitskiy Botanical Garden from Italy in 2012. The level of leaf infestation ranged from 20 to 300 galls per leaf ( $104.3 \pm 14.1$ on average), $97 \%$ of leaves were severely damaged (more than 40 galls per leaf).

Key words: Ophelimus maskelli, Crimea, Eucalyptus, first record, invasion.

УДК 632(470.23)

doi: 10.31360/2225-3068-2018-67-226-232

\section{ДИНАМИКА ОЧАГОВ \\ ГОЛЛАНДСКОЙ БОЛЕЗНИ ВЯЗОВ В Г. САНКТ-ПЕТЕРБУРГЕ}

Щербакова Л. Н., Мощеникова Н. Б., Шевченко С. В.

$$
\begin{gathered}
\text { Федеральное государственное бюджетное } \\
\text { образовательное учреждение выстего профессионального образования } \\
\text { «Санкт-Петербургский государственный лесотехнический университет } \\
\text { им. С. М. Кирова», } \\
\text { г. Санкт-Петербург, Россия, е-таil: Stcherbakova@mail.ru }
\end{gathered}
$$

Вязы (Ulmus L., Ulmaceae) занимают ведущее место в озеленении СанктПетербурга. По результатам проведённого обследования на территории города в настоящее время зарегистрирован и отмечен на карте 1461 очаг голландской 